\title{
An Evolutionary Ecological Perspective on Demographic Transitions: Modeling Multiple Currencies
}

\author{
BOBBI S. LOW, ${ }^{1}$ CARL P. SIMON ${ }^{2}$ AND KERMYT G. ANDERSON ${ }^{3}$ \\ ${ }^{1}$ School of Natural Resources and Environment Population Studies Center, The University of \\ Michigan, Ann Arbor, Michigan \\ ${ }^{2}$ Department of Mathematics, School for Public Policy, and Center for the Study of Complex \\ Systems, The University of Michigan, Ann Arbor, Michigan \\ ${ }^{3}$ Population Studies Center, Institute for Social Research, The University of Michigan, Ann \\ Arbor, Michigan
}

\begin{abstract}
Life history theory postulates tradeoffs of current versus future reproduction; today women face evolutionarily novel versions of these tradeoffs. Optimal age at first birth is the result of tradeoffs in fertility and mortality; ceteris paribus, early reproduction is advantageous. Yet modern women in developed nations experience relatively late first births; they appear to be trading off socioeconomic status and the paths to raised SES, education and work, against early fertility. Here, [1] using delineating parameter values drawn from data in the literature, we model these tradeoffs to determine how much socioeconomic advantage will compensate for delayed first births and lower lifetime fertility; and [2] we examine the effects of work and education on women's lifetime and agespecific fertility using data from seven cohorts in the Panel Study of Income Dynamics (PSID). Am. J. Hum. Biol. 14:149-167, $2002 . \quad$ ๑ 2002 Wiley-Liss, Inc.
\end{abstract}

More is known about human populations than about populations of any other species. In addition, with six billion humans on the planet, and diverse and rapid changes in demographic patterns, there is deep concern about the ability to make and test predictions about population patterns, causes, and effects. Biologists and demographers both study patterns of population growth, births, and deaths-however, because they typically ask different questions, their measurements tend to differ. Demography, as a social science (Caldwell, 1996), has focused on proximate determinates of aspects of fertility and mortality; the importance of such knowledge to a variety of concerns has led to internal tensions and cross-fertilization in various endeavors whose practitioners call themselves demographers (e.g., Kirk, 1996). In some ways, the analyses of biologists concerned with life history theory and patterns (Roff, 1992; Stearns; 1992; Charnov, 1993), even those who examine human life histories (Hill, 1993; Low, 1998) are simpler. Although they may explore mechanisms, they focus more on trait-environment correlations (see also Bock, 1999): Under what circumstances do particular patterns occur? The concerns involve explaining variation in behavior as a function of ecological (including social) context; adaptive payoffs are crucial.
In general, biologists focus on "net" results as the outcomes of differing strategies-aggregating influences, but disaggregating results, whereas demographers disaggregate variables (birth rates and death rates, rather than number reaching independence, for example), and aggregate results. It is thus sometimes hard to compare, or to translate, from one mode to the other. Both perspectives have great utility, depending on the questions asked; they differ in the level at which explanations are sought-and thus their explanations are complementary, rather than alternatives.

Combining the two levels of endeavor could be profitable (e.g., Bock, 1999). Certainly demography is crucial to life-history analysis. Stearns (1992, p. 20) called it the "key to life history theory, allowing us to calculate the strength of selection on life history traits for many conditions" Life history theory, with its generation of specific and testable hypotheses derived from theoretical expectations, may be useful if we can sufficiently delineate predictions for complicated human situations.

Correspondence to: Bobbi S. Low

Received 11 September 2000; Revision received 23 September 2001; Accepted 5 October 2001 


\section{TRANSITIONS AND CURRENCIES}

Although sociologists, demographers, and evolutionists calculate the costs and benefits of children in somewhat different currencies, and are differentially concerned with proximate versus ultimate causality (cf. Caldwell, 1982a,b; versus Turke, 1989, 1992; Kaplan, 1994, 1996), all are concerned with testable hypotheses about the determinants of fertility. All struggle with the conundrum that current human populations appear to be operating under different rules than other species or traditional human societies (e.g., Caldwell 1982a,b, 1983; Decker and Lewis, 1974; Borgerhoff Mulder, 1998; Kaplan.et al., 1995; Alexander, 1979, 1987, 1988; Low, 1993; Luker, 1996; Geronimus, 1996a,b).

In other species, despite great variation, the evolution (including phenotypic plasticity) of age-specific fertility, clutch and litter size, and parental investment in offspring all appear to follow consistent rules (Roff, 1992; Stearns, 1992) Beginning with these rules, counter-intuitive and testable predictions can be generated. So do some human populations. Traditional societies, as defined by anthropologists, are typically small-scale societies, often hunter-gatherers, fishers, pastoralists, horticulturalists, or agriculturalists (whether slash-andburn, irrigation, or other type). Around the world and in a variety of environments, such societies appear to follow the rules (e.g., Irons, 1979a,b, 1983; Chagnon, 1988; Borgerhoff Mulder, 1987, 1988a,b, 1995; Cronk, 1991a,b). Similarly, although data are more sparse, $19^{\text {th }}$-century European societies of the demographic transition that have been examined behaved in this way (Hughes, 1986; Røskaft et al., 1992; Voland, 1990; Voland et al., 1990; Voland and Dunbar 1995; Clarke and Low, 1992; Low, 1989, 1990, 1991, 1993; Low and Clarke. 1991, 1992, 1993).

Modern populations seem aberrant. Demographers have struggled for years with the complexities of fertility transitions, and every time a theoretical advance seemed imminent, new trajectories emerged (Schofield and Coleman, 1986; Friedlander et al., 1999). Post-transition societies appear to have fertility that is lower and later than any calculated optimum (Hill, 1993); and the characteristic positive association between resource control (including wealth) and fertility seems to be absent or reversed in many societies (Borgerhoff Mulder, 1998; Low, 2000a,b).

In what ways does modern human fertility require an explanation that is unique? Interpretation is difficult. Many studies lump as a single "population" groups whose members face very different constraints (see Low, 2000b). Studies of modern populations seldom measure variables in ways parallel to those of other species, traditional societies, and transition societies; frequently proxies such as education are used (see Low, 2000a,b).

Women generate their own income in new ways today, and this affects fertility tradeoffs. It is thus important to know the source of women's wealth: it might come from their husband's wealth (as in $19^{\text {th }}$-century Sweden, when a positive relationship existed), from women's own work (Tasiran, 1995, positive relationship), or from inheritance (Essock-Vitale and McGuire, 1988, positive relationship). Nothing prevents a diversity of strategies from coexisting, and none, some, or all may be adaptive, depending on circumstances. Consider a 1999 study reported in the New York Times (Hass, 1999) that compared income and fertility in nine New York neighborhoods. In three neighborhoods, wealth and family size were negatively related (families with three or more children had incomes less than $85 \%$ of the income of families with one child). In three neighbourhoods, the relationship was flat; and in three neighborhoods, families with three or more children had higher incomes than families with one child-in one neighborhood, three times the income of single-child families.

Rather than expect a singular condition, it might be more profitably ask: When and under what conditions can each of the above patterns be predicted to occur? A final complication is that wealth may influence both fertility and mortality (Geronimus, 1996b; Geronimus et al., 1996). While there are studies that examine parts of such relationships, there is little systematic treatment.

This paper uses dynamic simulation models to explore trade-offs in women's agespecific fertility, mortality, and earnings to construct populations in different (virtual) environments, and compares empirical data from real populations to examine the "fit" of general life history arguments to real-world 
data. In doing so, it is suggested that lineage persistence (Fisher's [1958] $m$ ) over time may relate to complex combinations of variables, and not simply to classic measures of fertility and survivorship. Empirical data from the Panel Study of Income Dynamics (PSID) are used to explore how the patterns play out in one modern data set.

\section{TRADE-OFFS AND TRANSITIONS}

Despite great variation across species in life history patterns, repeated analyses confirm that organisms have evolved to maximize, under constraint, their lineage success, although (see below) defining "success"- what to measure and when - is nontrivial. Typical constraints include effect of size and age on reproductive competition and maternal success, effect of interbirth interval on offspring success, and so forth. Even for nonhumans, the tradeoffs are not simple, but certain predictors are very strong (Roff, 1992; Stearns, 1992):

Age at first birth is most strongly predicted by extrinsic adult mortality (Stearns, 1992; Roff, 1992; Coale and Trussell, 1974, 1978), but is also constrained by energy available and the relative profit to further self-investment (Sibley and Calow, 1986). The greater the adult mortality (due to extrinsic factors not related to reproduction), the earlier the age at first birth; as chances to die before reproducing increase, optimal age at first birth decreases (Hill, 1993; Hill and Hurtado, 1996). Human patterns are consistent with this pattern. In traditional societies women are sub-fecund in their early teens, perhaps due to the costs of necessary further growth on limited nutrition (Lancaster, 1986), and in modern populations with high mortality rates (Rank, 1989; Geronimus, 1996a; Daly and Wilson, 1997), first births are quite early.

Litter biomass (in humans, neonatal weight) is influenced by adult size, which limits calorie throughput rate and controls both adult nutritional status and biomass possible in any reproductive bout. At a more refined level, within species (including humans), neonatal birth weight varies with maternal nutritional condition and health, and is related to juvenile mortality (Stearns, 1992; Roff, 1992).

Interbirth intervall evolves to that timing that yields the greatest number of living successful offspring. Too-short intervals may decrease a mother's ability to invest and produce insufficiently vigorous or competitive offspring (e.g., Stearns 1992, Roff, 1992).

Per capita parental investment: adult extrinsic mortality, offspring growth rate, and required per capita investment for successful independence all interplay to affect level, type, and duration of parental investment. This complicated set of relationships reduces to three observations. First, per capita investment declines when extrinsic adult mortality is high, ability to invest parentally is low or uncertain, and offspring that require high levels of parental investment are at risk. Second, when parents can provide significant investment, the offspring can reduce its own expenditures (e.g., to feed itself) and will grow more quickly than otherwise. Humans have raised this strategy to a fine art, because those other, than the mother may also feed juveniles. Finally, when competition is high, and heightened per capita investment is required for offspring success, fertility typically declines. MacArthur and Wilson (1967) called this " $r$ - and K-selection" (although their concept has been seriously perverted and misused); in other species this is typically density -related, although it need not be so (Low, 1993, 2000a,b). Darwin (1871, p. 319) noted that: "The only check to a continued augmentation of fertility in each organism seems to be either the expenditure of more power and the greater risks run by the parents that produce a more numerous progeny, or the contingency of very numerous eggs and young being produced of smaller size, or less vigorous, or subsequently not so well nurtured."

This trade-off between offspring quantity and offspring quality has been recognized by several disciplines, including biology (Lessells, 1991; Smith, 1974; Stearns, 1992), anthropology (Hill, 1993; Hill and Hurtado, 1996; Kaplan, 1996), economics (Becker, 1991; Willis, 1973), and sociology (Powell and Steelman, 1989).

Lifetime fertility is constrained by optimal per capita investment in offspring, optimal interbirth interval, and adult mortality schedules. Although within-species variation is great in humans, some of these relationships vary more than others, and are of more interest to us here. Some life-history arguments from the biological literature are too general, or phrased in 
inappropriate units for easy applicability to humans; this weakens arguments by analogy. Consider biomass per reproductive bout: in other species, the range of variation is sufficient to make testing this rather straightforward. In humans, single births are the norm, twins are rare, and triplets even rarer. On average, a pair of twins weighs more than a single birth, and each twin weighs less, fitting the general tradeoff model. The range of variation is so small in humans that attendant costs of reproduction (Stearns, 1992; Roff, 1992)-twins versus singletons - are difficult to estimate. Yet, controlling for other factors, low-birthweight infants suffer higher mortality than normal-birth-weight infants.

Here, in both the empirical data and the models, emphasis is on age-specific mortality, age-specific fertility, and the quantityquality trade-off. The last two lie at the heart of demographic transition analyses (Becker and Lewis, 1974; Decker, 1981, 1991; Borgerhoff Mulder, 1998). Many things can influence traits such as agespecific fertility (Roff 1992, Table 7.3); thus it is hardly surprising that, in different times and places, different causal variables have the strongest influences. In $19^{\text {th }}$ century Sweden, for example, daughters of wealthy men tended to marry wealthy men, and had higher age-specific fertility than poorer women (see Low, 2000b), despite specific variations among parishes. Daly and Wilson's (1997) study of 30 Chicago neighborhoods found another effect: as life expectancy declined, women reproduced earlier. Life expectancy itself is salient (Roff, 1992; Stearns, 1992): extrinsic adult mortality is a strong predictor of age at first reproduction. Daly and Wilson (1997) suggested that it is also psychologically salient. Whether conscious motivation is found in interviews, the pattern shown with life expectancy in the Chicago neighborhoods dramatically parallels that in other species. In this case, household income was largely irrelevant. The fact that different environmental variables may supply the influence in any particular case does not obviate the general rule: age-specific fertility is influenced by extrinsic pressures.

The "phenotypic correlation" (Lessells, 1991) can cause difficulties: even when it is clear that, for example, energy available for growth is unavailable for reproduction, individuals may exist that have so much energy available that they can both grow and reproduce more than others. Yet the degree of difficulty caused by the phenotypic correlation in other species pales by comparison to the difficulties it can cause in analysis of human populations (e.g., Hill and Hurtado, 1996). One could argue (Alexander, 1979, that the human species literally evolved to invent and proliferate new scenarios, new axes of competition. If true, this means that effort is likely to be directed toward cultural success even when it has become so elaborated that it shows no pattern with reproductive success, making analysis difficult. Discovering what objective function (if any) people are maximizing, and how that varies among groups, will be a complex endeavor.

Women face harsher trade-offs than men in resource-garnering activities, versus the production of children and dispersal of investment to them. Men in traditional societies typically show reproductive advantages with status and wealth (see Low, $2000 \mathrm{~b})$. In traditional societies, a woman's value was typically her reproductive value: how many children (reflected as daughters) will she produce in the remainder of her life, given the current age-specific fertility and mortality patterns (Fisher, 1958)? Bridewealth payments in at least some traditional societies correlate with women's reproductive value (Borgerhoff Mulder, 1988b).

In post-demographic transition societies, successful children cost more per capita in parental investment than they ever can return, and women may trade reproductive value for resource value (working and delaying fertility), so that one can wonder whether wealth affects each sex's reproductive success differently. Kaplan et al. (1995) and Kaplan and Lancaster (2000) found no relationship between wealth and fertility for modern Albuquerque men. It is at least theoretically possible that women may actually profit reproductively by spending more effort bringing in resources, compared to filling traditional roles of child production; certainly an increasing number of women are behaving as if this were true. Low fertility and costly children result.

Whether such women actually do profit reproductively is unknown. The investment level required to produce successful offspring varies with environment, and specifically with the threshold level of 
investment required for a child's success. Required investment correlates with the competition offspring face, whether this is simply a density issue (MacArthur and Wilson, 1967), an educational issue (Knodel et al., 1990), or a labor market issue (Kaplan, 1996; Low et al., 1992; Low 1993, 2000b; Low et al., in press).

Are there circumstances in which relatively wealthy women who have late and low fertility have greater net lineage increase or persistence than others? Fertility is so low, and so late for modern Western populations that it is difficult to imagine this strategy as increasing lineage representation or persistence, unless something other than numbers of children (e.g., numbers $\times$ resources controlled) is being maximized-and such a strategy could sufficiently reduce unpredictable extrinsic mortality to compensate for very low numbers and long generation time. That is, such lineages could only gain if they were so protected from mortality that their persistence was longer than other lineages that produced more children, but whose children died at a compensatory rate.

It is difficult to imagine gathering reliable empirical data sufficient to test this possibility fully. However, it can be modeled. What level of protection afforded by resources would be required for this strategy to work under specified conditions? The trade-offs can then be examined explicitly. Most currently available data, gathered to answer other questions, are inadequate (Low, 2000a). Although it is obvious that the problem is complex, the patterns among women's education, women's work, and fertility suggest that real trade-offs do exist. Both models and more finely honed empirical data, especially longitudinal data, are needed.

\section{MODELS AND DATA}

People today face more complex reproductive trade-offs than individuals in other species or people in traditional societies. It is not unreasonable to expect individuals to use heuristic "rules of thumb" in their choices, and to expect that such choices will sometimes, but not always, be optimizing. Several aspects of the relationships between resources (and education to get those resources) and (1) completed lifetime fertility and (2) timing of fertility (age-specific fertility) for women under different circumstances are examined. Dynamic modeling is used to simulate conditions reflected by the literature on such populations, and to ask under what conditions, if any, delayed fertility can result in longer lineage persistence and greater lineage growth, than early fertility. As is always true, simplifying assumptions are made.

\section{Model 1}

In Model 1, straightforward analyses of $r$, the intrinsic rate of increase (Roff 1992, Stearns 1992) are calculated. What shifts in age of first reproduction, age-specific fertility, and total fertility will cause the growth rate $r_{\mathrm{s}}$ of the early- and late-reproducers to converge? Leslie matrices were constructed of 100 women, 12.5 each in age groups $0-5$, $6-10,11-15,16-20,21-25,26-30,31-40$, and $40-45$ years. Initially, no women existed in the post-reproductive categories of $46-50,51-55,56-70$ years. These conditions form the basis of the following experiments.

1. Population growth rates are calculated for a series of populations of women, Whose reproduction was concentrated into one 10-year period (16-24, 21-30, 24-35, 31-40 years). Total daughters $\left(m_{x}\right)$ varied from 1.1 to 2.1 , and survivorship of those daughters in age $0-5$ years varied from 1.0 to 0.45 . Obviously, some combinations of age-specific fertility are unrealistic (e.g., two daughters-and by inference two sons, although they do not count in a life table-born to a woman between ages 36 and 40 years). Combinations are explored of fertility at the specified age and survivorship in the $0-5$ age class that result in equal population growth rates for women with different generation times.

2. In the real world, daughters may show fertility patterns that differ from those of their mothers. In this set of experiments, equal numbers of women with the fertility patterns explored in item 1 were the foundresses of a single large population. In each generation, daughters had some probability $(P)$ of shifting to a fertility distribution that was earlier $(0.01<P<0.02)$ or later $(0.05<P<0.08)$ than that of their mothers. After 150 5year periods (750 years), the population 
was examined: What was the current proportion of each fertility strategy, and what proportion of the current population descended from foundresses of each type? These simulations explore the longer-term effects of infant mortality and age-specific fertility.

\section{Model 2}

In these Leslie-like models, life paths are constructed for women who begin life under different conditions, and facing different constraints and trade-offs, depending on exigencies and past decisions. Not only the biological measures of Model 1, but social support, education, and wealth are tracked. The advantage of this more complicated model is that not only population size, but also the resources controlled by different categories of women in each time period, can be followed.

The currencies. Because trade-offs for women facing different conditions are a focus, the analysis begins by holding the fertility of all women equal, removing total fertility as a variable; only age-specific fertility varies. For the first of these models, all women have just more than one daughter in one age period. Despite the complexity it introduces, three "currencies" are used. Each compartment includes not only age, but also amount of social, human, and physical capital and parental status. Social capital, $S_{x}$ (one's parents, spouse, family and friends who can provide services), exists at two levels; it can increase in certain age groups (e.g., marrying), and decrease in any (loss of a parent, divorce). A loss of social capital (cf. Geronimus, 1996a,b, 1997; Daly and Wilson, 1997) is associated with lowered survivorship of any infants born to such mothers.

Human capital, $H_{x}$ (investment in education and skills), exists at five levels (elementary, middle school, high school, college, and graduate work). College incurs a current cost, with a delayed payoff of increased physical capital. Post-college education, in this model, mimics typical graduate work, in which the physical capital level is unlikely to change, rather than professional school, in which significant debt can be incurred. Everyone reaches $H_{x}$ levels 0 and 1 at age levels 0 and 1 respectively, but not everyone finishes high school (reaches $H_{x}$ level 3) (Fig. l). Physical capital, $K_{x}$ (one's monetary and other physical resources, roughly socioeconomic status; nine levels), increases the probability of gaining human capital, and thus, in time, further physical capital. For each currency, $x$ denotes the age group. There is evidence in the literature that social and resource capitals are traded off in some circumstances, and that social and human capital can influence reproductive decisions (above). Cultural diffusion cannot as yet be incorporated in this model.

The women. There are approximately 900 states in which a woman can exist as defined by the above currency levels. There are seven age groups, each of the first six approximately 5 years long: $0=$ birth through early elementary school; $\mathrm{I}=$ elementary school; $2=$ junior high school; $3=$ high school; $4=$ college age, $5=$ post-college age (late 20s); $6=$ early $30 \mathrm{~s} ; 7=$ late 30 s and beyond. There is a transition probability of moving from one state to any other state in a time period: for example, the probability of gaining $H_{x}$ or of surviving to the next age group increases with level of $S_{x}$ or of $K_{x}$. Giving birth or going to college in a period decreases $K_{x}$; otherwise women work (and increase $K_{x}$ unless they have dropped out before finishing high school). Higher $H_{x}$ leads to comparatively larger $K_{x}$ increases in later age groups. Low $S_{x}$ lowers the fertility for any opportunity, as do very low and very high $K_{x}$. (Copies of the probabilities used are available from the authors.)

The transition probabilities in this model are first estimated using published data. Consider three populations. First, poor women on welfare (Rank, 1989; Geronimus, 1996a,b; Daly and Wilson, 1997) are in $K_{x}=$ l-3. These women have lower survivorship both as children and adults (there is a 13\% chance that a woman will die before age 45 ) than other women-and for the daughters of women dying early, the loss of social capital is reflected in lowered infant survivorship. These women tend to have early fertility, tend to be and remain poor (Corcoran and Kunz, 1997), and are likely, because of relatively low survivorship, to lose members of their social network who provide social currency. Rarely do they transfer up more than one level of physical capital. When a pregnancy occurs early, schooling is terminated (or disrupted, for there is some 


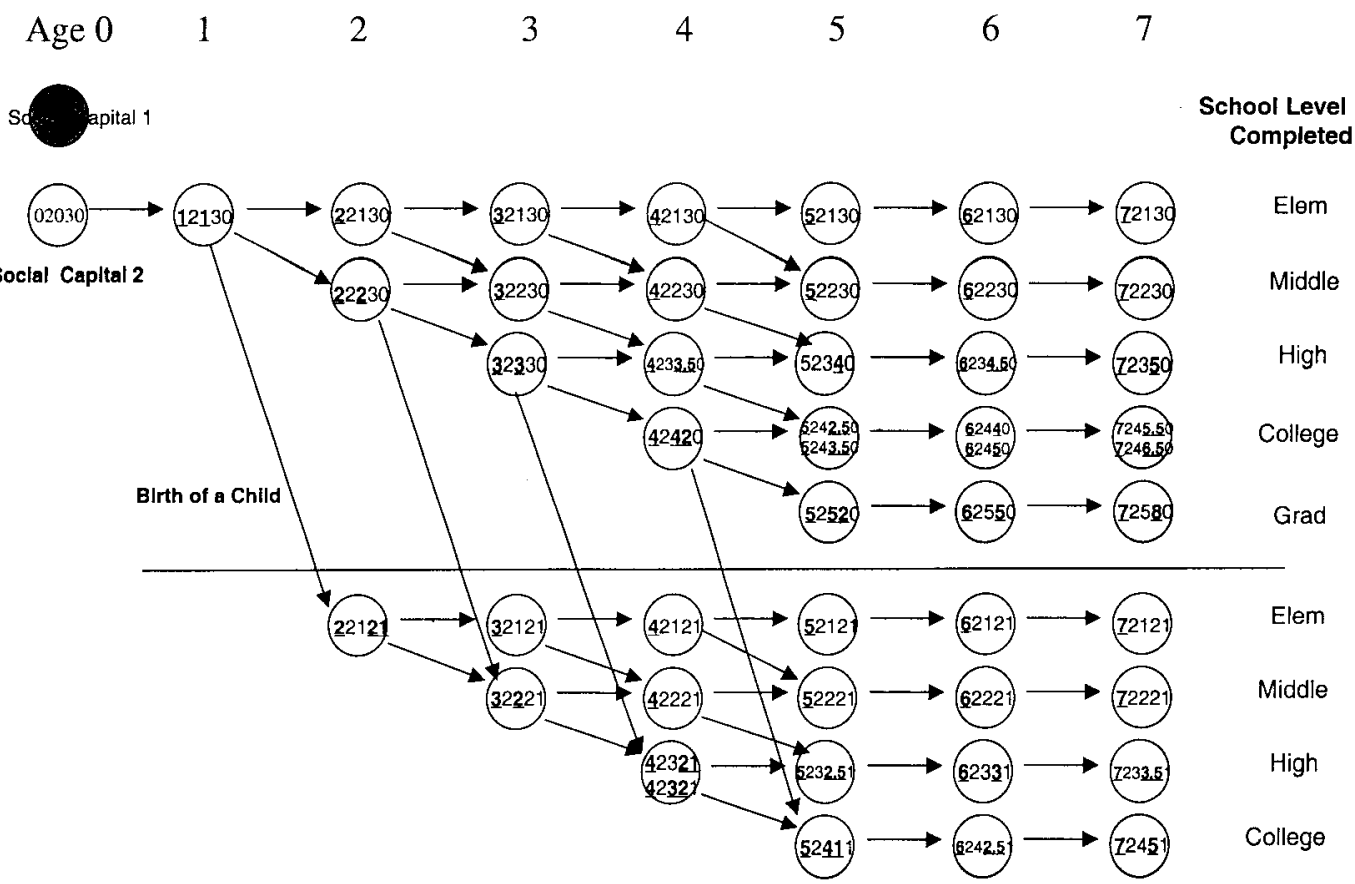

Fig. 1. In Model 2, there are nine levels of physical capital $\left(K_{\mathrm{x}}\right.$ treated here as roughly equivalent to socioeconomic status). There are two levels of social capital $\left(S_{\mathrm{x}}\right)$ within each physical capital level $(1=$ intact family; $2=$ impaired social or familiar network); five human capital ( $H_{\mathrm{x}}$ : education) levels (elementary, middle school, high school, college, and post-college); and seven ages, each of the first six approximately 6 years long $(0=$ birth through early elementary school; $1=$ elementary school; $2=$ junior high school and high school; $3=$ college age, $4=$ postcollege age (late $20 \mathrm{~s}) ; 5=$ early $30 \mathrm{~s} ;(6=$ late $30 \mathrm{~s} ; 7=$ over 40$)$. Thus a women may occupy more than 900 states. These states are described by a 5-digit string, in which position $1=$ age, position $2=$ social capital, position $3=$ human capital level, position $4=$ physical capital (1-9), and position $5=$ fertility $(0=$ no child, $1=$ child $)$. Here the possible life paths are shown for a girl born into physical capital level 3, social capital level 2 . Note that in some states, either two values exist for, e.g., physical capital, or all values are the same, but one is a new condition (reflected by bold and underlined type); these result when a woman's condition differs depending on the path she followed (e.g., giving birth, then returning to school, versus continuing to school and giving birth later).

probability of returning to school at later ages), and future physical capital acquisition is limited.

Second, women with "typical middleAmerican" trade-offs occupy $K_{x}=4-6$. They survive very well throughout life, and are likely to invest in acquiring both human and physical capital. Holding their fertility very close to are daughter (and by extension, one son), reflects very modern developed-nation fertility, in which $r \approx 0$. In the real world, this is occasionally locally higher for such women. Finally, professional women occupy $K_{x}=7-9$. Such professional women appear to be becoming increasingly common (Sellers, 1998). These women's fertility is typically late; their human and physical capital levels are high. The total fertility of these women is undoubtedly overestimated by beginning with a lifetime fertility equivalent to that of the other two groups. Within each of these three broad categories, a range of parameters is constructed (e.g., survivorship is lower for $K_{x}=1$ than $K_{x}=3$ ).

The Questions. In Model 2 the additional currencies of physical capital $K_{x}, S_{x}$, and $H_{x}$ are used to explore trade-offs. For example, Geronimus et al. (1997) suggest that teen births to socioeconomically disadvantaged women do not represent loss of social capital, because these births to teenagers typically represent whole-family decisions, not teenage rebellions, and kin networks allow sharing of both costs of childcare and risks of mortality (cf. Burton, 1990; Stack, 1974, 1996). Under what conditions will this occur? Using Model 2, several questions are 
explored. First, when women gain in physical capital by delaying reproduction for human capital (and their daughters are assigned the increased level), what are the relative rates of growth for women who delay fertility for the sake of education but nonetheless have as many children as others? When physical capital affects both mortality (poverty increased age-specific mortality) and fertility (both the very wealthy and the very poor have fewer children than middle-status women), how does the distribution of women and physical capital change?

\section{Empirical data}

To examine women's trade-offs between education and fertility empirically, data are used from the PSID, a longitudinal dataset that began in 1968 with a nationally representative sample of 5,000 U.S. households. Individuals from the original sample of households have been re-interviewed annually; people who leave core households to form new households are also followed, including spouses who divorced as well as children and grandchildren who have grown up. In 1990, the sample was refreshed with a representative national sample of 2,000 Latino households. The PSID is collected and maintained by the Survey Research Center of the Institute for Social Research at the University of Michigan. Currently, all data from 1968 through 1993 are publicly available, and may be downloaded from http:// www.isr.umich.edu/src/psid/.

Each annual wave of the PSID collects core data on income sources and amounts, employment, family composition changes, and demographic events. Beginning in 1985, the PSID began collecting comprehensive retrospective fertility and marriage histories of individuals in the sample households. For 3,902 women ages 45 and older, these data are used to examine the following relationships: lifetime reproductive success, the probability of not having children, the age at first birth, educational attainment, birth cohort, and ethnicity.

\section{RESULTS}

\section{Model 1: Trade-offs in $I_{x}, m_{x}$, and age at first reproduction}

The power of generation time is starkly evident in the first runs. When equal numbers of women are compared who share the same mortality schedule and have identical total fertility, but different birth schedules, the youngest-reproducing women quickly swamp the other populations. Furthermore, even when most daughters are quite likely to switch to later fertility schedules than their mothers, after 750 years, $90 \%$ of the population are early-reproducers, and most women $(61 \%)$ in the population, no matter what their own reproductive timing, are derived from foundresses with early fertility.

Coale (1974), using total fertility rate, life expectancy, and annual birth rate, noted that many combinations of fertility and mortality can generate a population in equilibrium. Trade-offs differ in growing or declining populations, however. For example, as Roff (1992, p. 240) noted, when the rate of increase is high, selection acts more strongly on time to maturity than on fecundity. This is an observation relevant to family planning programs in developing nations with currently high rates of increase.

In Fig. 2, three population growth/decline rates are shown for four groups of women. In the runs generating these curves, all mortality is either pre-reproductive or long post-reproductive and the only difference across groups is the (somewhat unrealistic) condition that all reproduction $\left(m_{x}\right)$ in a group is concentrated into one of four age periods (16-20, 21-25, 26-30, and 31-35 years). Two things should be clear, and both are relevant to issues of population patterns in developed versus developing nations today. First, the farther $r$ departs from zero, the more divergent are the combinations of $l_{x}$ (survivorship at age $x$ ) and $m_{x}$ (fertility at age $x$ ) that generate comparable $r$ values, for women who reproduce at different ages (the more spread out are the curves). In rapidly growing populations, for example, a greater shift in mortality is required to offset a specific difference in age-specific fertility than in population close to equilibrium (see also Roff 1992, p.240). At $r=0$, all curves converge to become one, and at equilibrium, the population has a stable and stationary age distribution.

Second, not only do the curves as a group shift (Fig. 2a-c) at different $r$ values, but their order shifts. In a population increasing by $5 \%$ (Fig. 2a), consider those with an $m_{x}$ of 1.6: the group of women reproducing 
in ages $16-20$ years have an $l_{x}$ (in the prereproductive age group) of 0.76 . For the $31-$ to 35-year-old reproducers to meet the same rate of increase with the same $m_{x}$ of 1.6 , their $l_{x}$ would have to be 0.88 . Similarly, when late- and early-reproducing women have similar survivorship (here, $l_{x}=1$ ), the late-reproducing women (31-40) must have 1.16 daughters for every daughter produced by a woman who reproduces at age 16-24 years.

Conversely, when the population is decreasing by $5 \%$ (Fig. 2c), the relative positions of 16-year-old reproducers and 31 to

A.

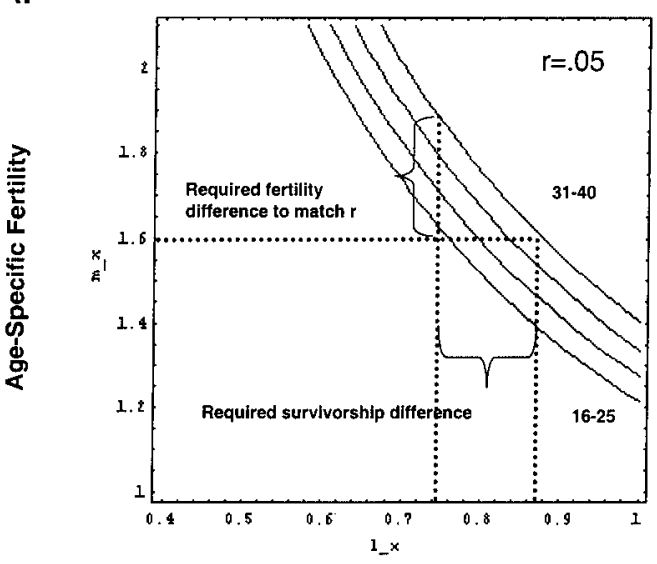

Age-Specific Survivorship

B.

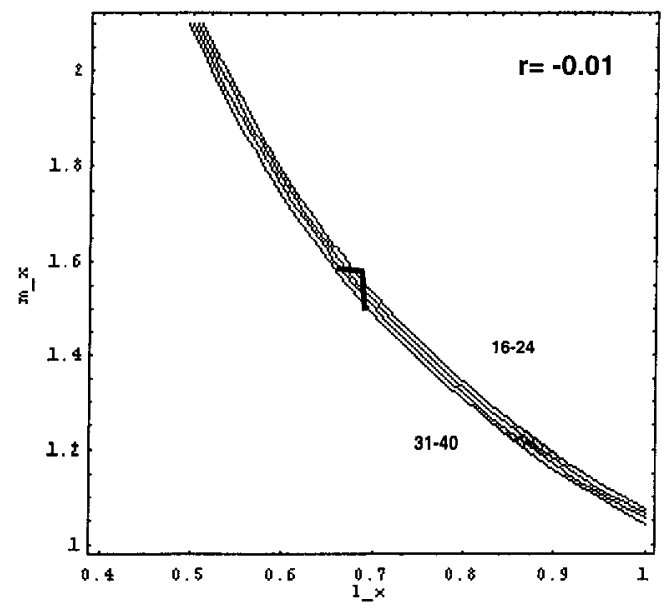

C.

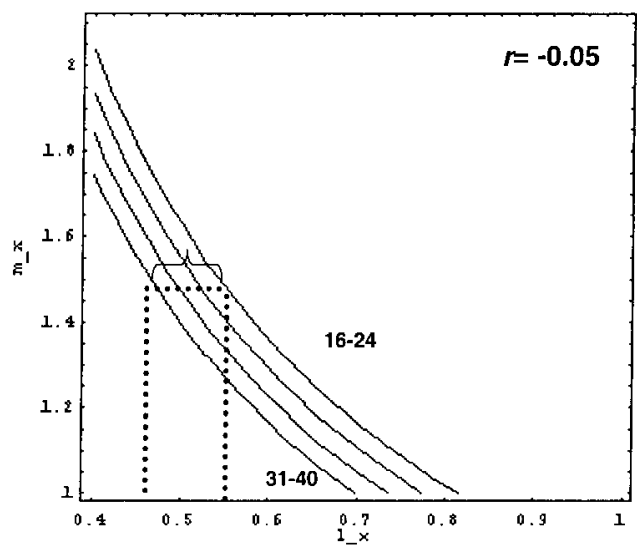

Fig. 2. As populations diverge from equilibrium, trade-offs in fertility and mortality become more extreme, and age-specific responses matter more. Here, $m_{x}$ is concentrated in one of the following periods: $16-20,21-25,26-30$, and $31-35 ; l_{x}$ is less than 1.0 only in the $0-5$ and 70 age groups. These are "iso-r" curves: at any point along a given curve, that combination of $l_{x}$ and $m_{x}$ for women reproducing in that age group will result in the same value of $r$. The curves become identical when $r=0$, and the order of the curves reverses, depending on whether $r$ is $<0$ or $>0$ (Fisher, 1958). The more rapidly a population is expanding (the greater is $r$ $>0$ ), the more children must be produced by women who waited to reproduce, in order to "match" each child borne by a woman who reproduces early. See text for further discussion.

35-year-old reproducers are reversed (see Fisher 1958, who commented on the shift in reproductive value in increasing and decreasing populations). Thus, in increasing populations, women who delay reproduction must have markedly higher fertility or far better survivorship that women who reproduce early, in order to generate the same contribution to population growth. In declining populations, late-reproducers decline more slowly than early reproducers.

\section{Model 2: Additional currencies, life paths, and population patterns}

The most striking result from this model was how extreme the effects of social, human, and physical capital must be in order to counter the advantages of early reproduction demonstrated in Model 1. In Model 2 , comparisons within levels of physical capital $\left(K_{x}\right)$ levels showed that early-reproducing women left the most descendants, generation after generation. However edu- 
cation (human capital) and socioeconomic status (roughly, physical capital) could influence both age-specific mortality and fertility.

Interactions of social, human, and physical capital influenced both age-specific fertility and age-specific mortality in Model 2. Conditions exist under which delaying reproduction (Roff, 1992) could be profitable, but these are constrained. As is true generally (and for Model 1, with appropriate parameter values), late-reproducers in declining $(r<0)$ populations do not see their lineages decrease as rapidly as those of early reproducers; this is hardly of interest to us here. In one set of runs of Model 2, the three lowest physical capital levels suffered very high mortality rates (30-50\%) at every age. Beginning with newborns in $K_{3}$, surviving women gave birth: all in age group 2 , all in age group 3 , all in age group 4 , or all in age group 5. Lifetime fertility was set sufficiently high (1.6 daughters) to allow a positive $r$ for the total population. Women who survived to give birth in age group 2, 3, or 4 could not escape the high mortality of lower income groups, but women who delayed birth until after "college age" (and many of these attended college) could move to $K_{x}$ levels (4 and above) with attendant high survivorship. These women-and only these women-had rapidly growing subpopulation numbers and wealth. The combination of very high mortality and early fertility for low education and socioeconomic categories, versus very low mortality for high educational and socioeconomic status, produced a gain for women who delayed reproduction. This is a tempting avenue to explore; however, empirical data (Geronimus, 1996b, 1997; Geronimus et al., $1996,1997)$ suggest that this is a very difficult path for poor urban women in the United States.

In Fig. 3A, mortality varies with both $K_{x}$ and $S_{x}$ levels, particularly for younger ages. Increased $H_{x}$ (education) both delays fertility and increases physical capital level at the completion of school. Women with more physical capital have better survivorship than others, but tend to give birth later; women with lower social capital $\left(S_{1}\right)$ have, within each level, slightly lower fertility than women with $S_{2}$. All women have 1.1 daughters. With these constraints, $r=1.08$, and after 40 rounds (roughly 200 years), wealthier women comprised an increasing proportion of the population: women with the three highest levels of physical capital comprised $50 \%$ of the population (most in levels 7 and 8). These women controlled over $70 \%$ of the existing physical capital, which had increased by about 50\%. They increase in part because women who go to school (and thus increase their later physical capital) have upward mobility (and collect in higher levels of physical capital) - and daughters are assigned the levels of their mothers upon birth. So the model produced somewhat high degrees of upward mobility.

Figure 3B introduces age-specific fertility reflecting data for white U.S. women, by education, from the PSID; women with less physical capital (and less education) not only have earlier fertility, but higher total fertility. In the runs of Fig. 3b, women with $\mathrm{K}_{3}$ and $S_{2}$ had a total of 1.35 daughters. With these constraints, $r=1.01$. After 40 rounds the population had increased by $29 \%$ while $K_{\mathrm{x}}$ had decreased by $4 \%$; women in the three poorest groups comprised more than $50 \%$ of the population, but owned only $20 \%$ of the wealth.

\section{Empirical data: The panel study of income dynamics PSID}

Women face life history trade-offs: acquiring human and physical capital has reproductive costs, similar to the trade-offs between body size and age of sexual maturity observed in non-market societies and nonhuman animals. Models 1 and 2 give some general support to that notion. But how do women actually behave?

The empirical evidence is clear that women in the United States do, in fact, behave as if such trade-offs exist. Lifetime reproductive success varies across birth cohorts and by race and ethnicity; some of the results presented here ignore these effects, although the multivariate analyses presented at the end of the section control for these important confounds. All analyses are restricted to women age 45 years and older. There are strong observed trade-offs between lifetime reproductive success (defined as the number of live births) and the age at first birth and first marriage (Fig. 4). Delaying first birth from age 15 to age 30 or age 45 years results in a concomitant reduction of lifetime fertility of approximately 2.1 and 3.8 children, respectively, while 

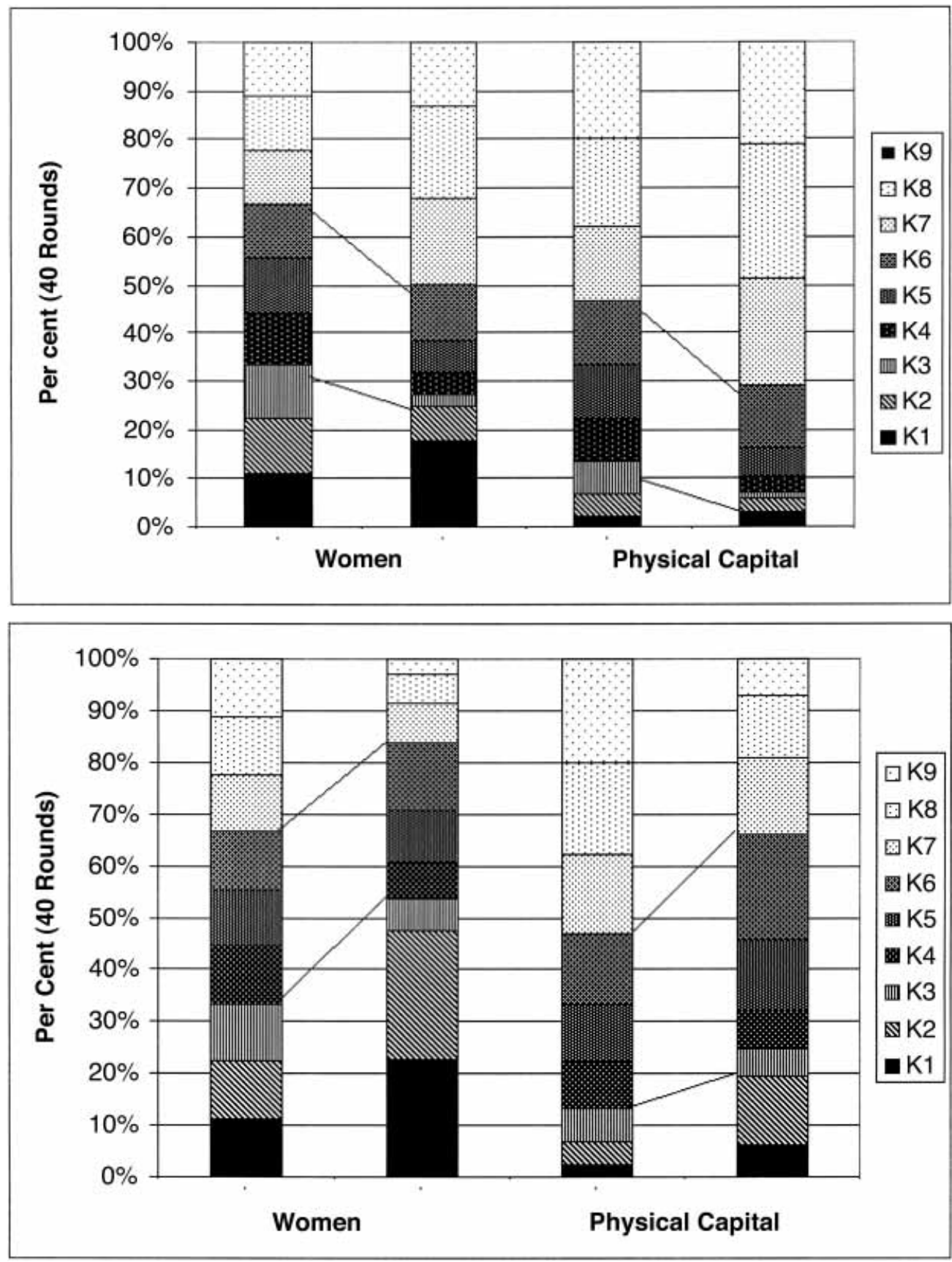

Fig. 3. Results of two runs of Model 2. (A) Mortality varies with both $K_{x}$ and $S_{x}$ levels, particularly for younger ages, following the literature for guidance. Increased $H_{x}$ (education) both delays fertility and increases physical capital level after the completion of school. Women with more physical capital have better survivorship, but tend to give birth later; women with lower social capital $\left(S_{1}\right)$ have, within each level, slightly lower fertility than women with $S_{2}$. All women, regardless of socioeconomic state or age at reproduction have 1.1 daughters, (B) Women with less physical capital (and less education) not only have earlier fertility, but higher total fertility; this is perhaps slightly more like the real world. 


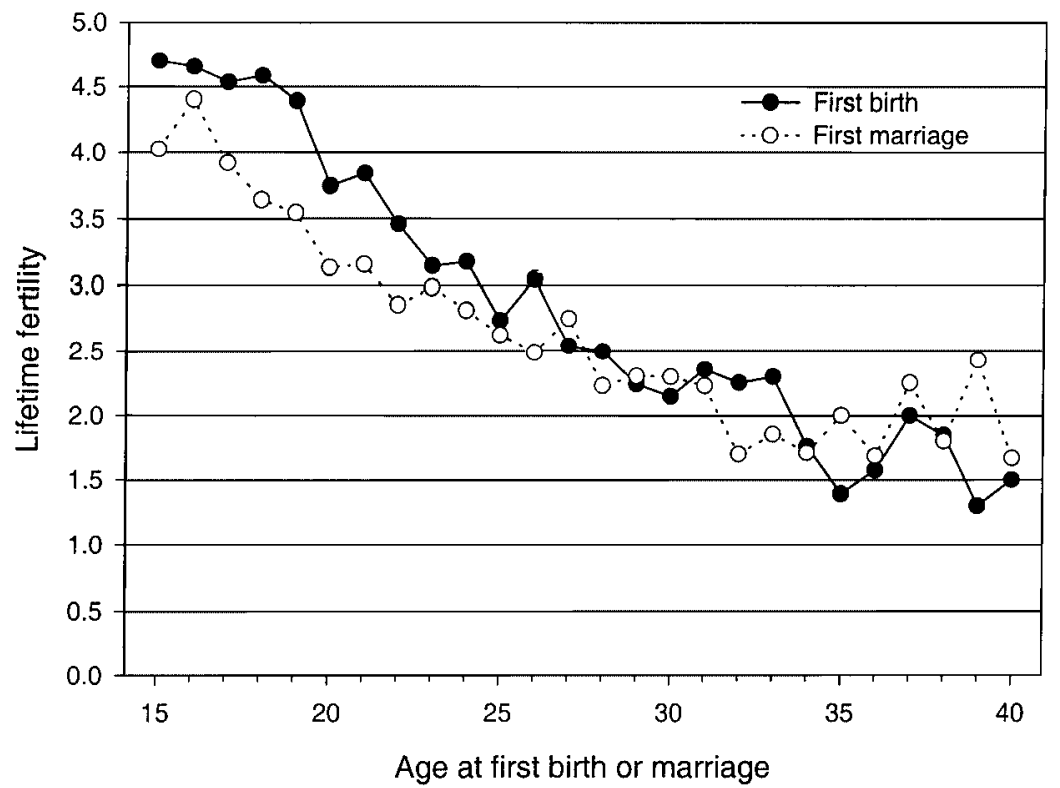

Fig. 4. Lifetime reproductive success (here defined as number of live births) as a function of age at marriage and age at first birth. Data from Panel Study of Income Dynamics (PSID).

TABLE 1. Lifetime reproductive success for women age 45 years and older, by highest education and birth cohort

\begin{tabular}{lccccccc}
\hline \multicolumn{7}{c}{$(N=3,902)$} \\
& No HS & Some HS & $\begin{array}{c}\text { HS } \\
\text { degree }\end{array}$ & $\begin{array}{c}\text { Some } \\
\text { college }\end{array}$ & $\begin{array}{c}\text { College } \\
\text { graduate }\end{array}$ & $\begin{array}{c}\text { Post } \\
\text { graduate }\end{array}$ & $\begin{array}{c}\text { All education } \\
\text { levels }\end{array}$ \\
\hline$<1920$ & 3.23 & 2.57 & 2.29 & 1.95 & 1.68 & 2.00 & 2.55 \\
$1920-24$ & 4.00 & 4.16 & 3.20 & 2.43 & 2.82 & 1.76 & 3.36 \\
$1925-29$ & 4.51 & 3.91 & 3.35 & 4.05 & 3.24 & 2.24 & 3.78 \\
$1930-34$ & 4.27 & 4.58 & 3.25 & 3.16 & 2.55 & 2.00 & 3.60 \\
$1935-39$ & 3.61 & 4.29 & 3.08 & 3.19 & 2.35 & 1.89 & 3.35 \\
$1940-44$ & 3.66 & 3.23 & 2.67 & 2.15 & 2.15 & 1.66 & 2.09 \\
$1945-49$ & 3.37 & 3.08 & 2.39 & 1.99 & 1.87 & 1.70 & 2.34 \\
All cohorts & 3.69 & 3.56 & 2.80 & 2.44 & 2.16 & 1.82 & 2.94 \\
\hline
\end{tabular}

HS, high school.

similar delays in the age at first marriage decreases lifetime fertility by 1.5 and 2.4 children, respectively. From a fertility perspective, then, there are important costs to delaying the onset of reproduction.

Tables 1-3 present further evidence of this trade-off. Lifetime reproductive success among women in the PSID sample varies by birth cohort, with women born before 1920 (whose peak fertility years occurred during the Depression and WWII) and women born after 1945 (the oldest of the baby boomers) having the lowest fertility (Table 1). There are also significant effects of educational attainment: fertility decreases with each incremental level of education, an effect that is seen within cohorts as well as across them. Women clearly trade off education and fertility.

Across cohorts, the age at first birth decreases, reaching a minimum for women born in the 30s, and then increasing for later cohorts (Table 2). Lower levels of education (high school degree and below) have similar ages of first birth; women with some college, college degrees, or post-graduate education, however, have increasingly delayed ages at first birth. Women apparently do face tradeoffs between acquiring an education and beginning their reproductive careers.

The proportion of women with no genetic children varies by cohort and educational 
TABLE 2. Age at first birth for parous women age 45 years and older, by highest education and birth cohort $(N=3,339)$

\begin{tabular}{|c|c|c|c|c|c|c|c|}
\hline & No HS & Some HS & HS degree & $\begin{array}{l}\text { Some } \\
\text { college }\end{array}$ & $\begin{array}{c}\text { College } \\
\text { graduate }\end{array}$ & $\begin{array}{c}\text { Post } \\
\text { graduate }\end{array}$ & $\begin{array}{l}\text { All education } \\
\text { levels }\end{array}$ \\
\hline$<1920$ & 22.4 & 23.3 & 24.7 & 25.7 & 28.2 & 30.8 & 24.1 \\
\hline $1920-24$ & 21.8 & 22.9 & 24.1 & 26.3 & 26.1 & 27.5 & 23.9 \\
\hline $1925-29$ & 22.5 & 22.0 & 23.1 & 23.3 & 25.1 & 24.8 & 22.9 \\
\hline $1930-34$ & 21.6 & 19.7 & 22.3 & 23.4 & 24.6 & 23.7 & 22.0 \\
\hline $1935-39$ & 21.8 & 19.4 & 21.9 & 22.9 & 24.5 & 23.9 & 21.7 \\
\hline $1940-44$ & 22.8 & 20.3 & 21.9 & 23.0 & 24.9 & 24.3 & 22.3 \\
\hline $1945-49$ & 22.5 & 19.7 & 22.1 & 22.6 & 26.2 & 27.6 & 22.8 \\
\hline All cohors & 22.3 & 21.0 & 22.7 & 23.5 & 25.9 & 26.5 & 22.9 \\
\hline
\end{tabular}

HS, high school.

TABLE 3. Proportion of women age 45 years and older with no children, by highest education and birth cohort $(N=3,831)$

\begin{tabular}{|c|c|c|c|c|c|c|c|}
\hline & No HS & Some HS & $\begin{array}{c}\text { HS } \\
\text { degree }\end{array}$ & $\begin{array}{c}\text { Some } \\
\text { college }\end{array}$ & $\begin{array}{l}\text { College } \\
\text { graduate }\end{array}$ & $\begin{array}{l}\text { Post } \\
\text { graduate }\end{array}$ & $\begin{array}{l}\text { All education } \\
\text { levels }\end{array}$ \\
\hline$<1920$ & 0.20 & 0.24 & 0.20 & 0.22 & 0.34 & 0.35 & 0.23 \\
\hline $1920-24$ & 0.19 & 0.17 & 0.10 & 0.17 & 0.12 & 0.24 & 0.16 \\
\hline $1925-29$ & 0.13 & 0.08 & 0.05 & 0.05 & 0.00 & 0.36 & 0.09 \\
\hline $1930-34$ & 0.07 & 0.07 & 0.07 & 0.11 & 0.14 & 0.25 & 0.09 \\
\hline 1935-39 & 0.10 & 0.01 & 0.08 & 0.11 & 0.12 & 0.39 & 0.10 \\
\hline $1940-44$ & 0.09 & 0.09 & 0.07 & 0.13 & 0.18 & 0.26 & 0.11 \\
\hline $1945-49$ & 0.07 & 0.07 & 0.08 & 0.14 & 0.18 & 0.23 & 0.12 \\
\hline All cohorts & 0.14 & 0.12 & 0.09 & 0.14 & 0.18 & 0.27 & 0.13 \\
\hline
\end{tabular}

HS, high school.

level (Table 3). As with total fertility and age at first birth, women born in the earliest and latest cohorts are more likely not to have any children than those in the 1925-1934 cohorts. For most cohorts, acquiring an education is associated with increased probability of having no children: women with college degrees and beyond are the most likely not to have any children. However, for one cohort-women born in the late 1920s, who are the mothers of many of the baby boomers - there is a negative relationship between childlessness and education, up through college graduates. Women with postgraduate education, however, remained the most likely to be childless in this, and every, cohort.

These results suggest women do indeed face trade-offs among acquiring education, beginning their reproductive careers, and their total reproductive success. In particular, women delay their first births - forego reproduction altogether -in the pursuit of education. Because these relationships are confounded by race and by birth cohort effects, Table 4 presents multivariate models that control for these background variables. The first column presents a model of lifetime reproductive success, for women who had at least one child. With respect to birth cohort, there is an inverted U-shaped relationship: relative to women born before 1920, women born in the 1920s and early 1930s have higher fertility, and women born in the 1940s have lower fertility. Hispanic fertility is similar to that of non-Hispanic whites, whereas African Americans have higher fertility (approximately 0.82 additional offspring). Women who were married at least once have about 0.77 additional genetic offspring. However, consistent with the relationship plotted in Figure 4, each additional year's delay in the age at first birth decreases women's lifetime fertility. Educational attainment is treated as a series of dummy variables, with the baseline category being women with high school degrees only. Controlling for lifetime marital status and age at first birth, women with less than a high school diploma have significantly more children, whereas there are no significant differences between women with higher levels of education.

These results suggest that education's influence on lifetime fertility (Table 1) works through a delay in the age at first birth (Table 2); once first birth is controlled for, higher levels of education are not associated with decreased lifetime fertility, at least for women who had at least one child. 
TABLE 4. Multivariate models of total lifetime fertility (for parous women) and the probability of having no genetic offspring, for women age 45 years and older, using the PSID

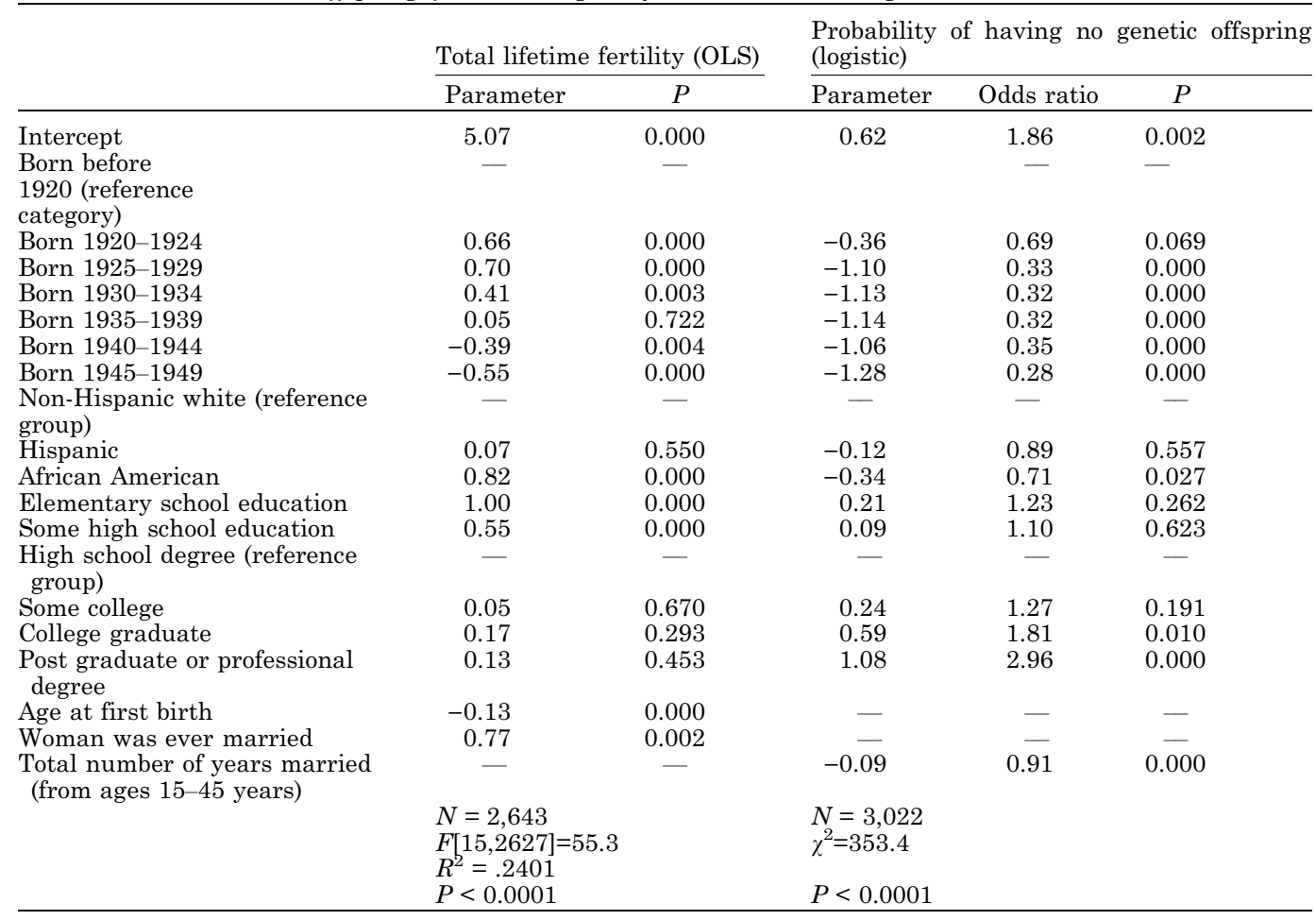

The second half of Table 4 examines the probability of women not having any genetic offspring over the course of their lives. Relative to women born before 1920, women in all later cohorts are less likely to be childless. Relative to non-Hispanic whites, African American women are less likely not to have children, whereas Hispanic women are neither more nor less likely. The analysis also controlled for the total number of years women were married between the ages of 15 and 45 years. Each additional year of marriage decreases the odds that a woman remains childless. Unlike total fertility for parous women, there are significant effects of higher education on the probability of not having any children. All else being equal, women with some college or with less than a high school degree are neither more nor less likely to be childless than women with high school degrees. However, relative to women with high school education, women with college degrees are 1.81 times as likely to be childless, and women with post graduate education are 2.96 times as likely not to have children.
The results suggest that women who acquire higher levels of education delay their ages of first birth, with consequent costs to their lifetime reproductive success. Controlling for the age of first birth, higher levels of education do not affect overall fertility for parous women, although the highest levels of fertility are observed for women with less than high school degrees. By delaying the onset of fertility to obtain higher degrees, however, women greatly increase their probability of not having any children at all. These results confirm that women do face trade-offs between fertility and education, and that there are fitness costs to delaying the onset of their reproductive careers.

\section{DISCUSSION}

George Williams, in his classic Adaptation and Natural Selection (1966), laid out the biologist's (and, now, perhaps the demographer's and anthropologist's) dilemma: despite the simplicity of natural selection's rules, even for nonhuman species, how can 
we best define "success"? Not by offspring born-many may die before independence or reproduction, rendering the parent's efforts inefficient. By grandchildren? How difficult, even in many short-lived species. As one imagines measures extending over a longer period, other problems arise: population numbers are difficult to interpret for species that experience great fluctuations; persistence through time measures something quite different-species such as horseshoe crabs are, by this measure, eminently successful.

Biologists have treated this heuristically: they measure what is possible and logically defensible as likely to contribute to lineage success - genes identical by descent-over time. Thus, a plethora of measures and interpretations exists. Like the work of others (e.g., Borgerhoff Mulder, 1998; Mace, 1993, 1996, 1998; Kaplan et al., 1995; Kaplan and Lancaster, 2000; Rogers, 1990, 1991, 1995), these simulations, and analysis of the PSID data, suggest that there are special additional problems in examining human populations, related to the human ability to create new currencies, and to change relative advantages in different environments.

In the evolutionary history of all living things, including humans, "more" has always been reproductively more profitable: either more babies, or better-provisioned-and thus more consumptive-babies. This distinction is crucial: for many species in highly competitive or densely populated environments, the most successful reproductive tactic in many environments is not to make the maximum number of offspring, but to make fewer, better-invested offspring. If poorer parents cannot substantially enhance their children's success, then large families, concentration of resources in one or a few children, with others leaving early (behavioral ecologists would call this an "alternate strategies" situation, demographers the "Mediterranean" family pattern) might be expected. Couples at the high end of the socioeconomic "ladder" might do better by investing more per child to make them competitive with their peers (e.g., education, clothing, status acquisitions; cf. Emlen, 1997). Evolutionary anthropologists (Kaplan, 1996; Kaplan et al., 1998; Kaplan and Lancaster, 2000), have analyzed the effects of cohort, wealth, and markets on human fertility (see also Stearns, 1992; Roff, 1992; Hill, 1993).
The next question, of course, is, "under what environments do each of these strategies succeed, and when do they fail?"

At first, the fertility and consumption shifts that characterize developed nations today look tantalizingly like low-fertility-high-investment parental competition strategies. (Scholars estimate that a child born in the United States today will consume 15 times as much as a third-world infant.) Rogers $(1990,1991,1995)$ has modeled aspects of such trade-offs. Sociological studies (Knodel et al., 1990) also suggest that parents may explicitly calculate the number of children they can afford to have, given the level of parental investment required to make those children desirable in the labor market.

No environment is limitless. However, the typical measure is "numbers of individuals over time," with the assumption (when this problem is even considered) that variance in lineage success and persistence lies there-in numbers. For other species, this is often a reasonable assumption. Humans, however, have elaborated mechanisms of resource acquisition and control to the point that they have generated extreme variance, unknown in other species, in the amount of resources controlled per individual.

As a result of the simulations, another way is apparent to consider the effect of resource limits, or carrying capacity, on human populations. Consider the product (numbers $\times$ resources controlled) to compare lineages. For humans, this term can have considerable more variance in the "resources" component compared to the "numbers" component. This is clearly an issue in the real world (Heilig, 1996; Cohen, 1995, 1998; MacKellar, 1996, 1997): the number of people one calculates that the world's resources can support depends largely on assumptions about per capita consumption, and to some extent about assumptions regarding equity of resource distribution. This was the core of the arguments between developed and developing nations at the Rio Conference (See Low et al., in press).

In terms of persistence through time one measure biologists have used to measure "success", the effect of resources on human lineage persistence may have been far greater than for any other species, and far greater than we have ever suspected. In addition, although resources controlled per 
capita may not have much influence (even though variance is high) in developed nations today, the story in developing nations may be different.

Furthermore, if resources become more constricted in the future, access to limited resources may not be even, or equitable (cf. Hardin, 1968; Boone and Kessler, 1999). At that point, resource allocation rules would become crucial: if allocations go first to richly endowed, high-consumption individuals, the population composition at carrying capacity has relatively few members of lowendowment lineages. Thus, if "them that's got shall get" (precisely the complaint of the developing nations at the Rio Conference), the number of individuals at equilibrium will be relatively low, the poor will lose, and our human preoccupation with resources for their own sake may make more selective sense than we have imagined (Low et al., in press).

In traditional societies, wealth or status principally affected a man's ability to get mates (review by Low, 2000b). Offspring survival was, in most cases, not affected by a man's status. Data from western societies today typically show a significant difference in survival at many ages with measures of income (Daly and Wilson, 1997), but fertility data are more mixed (Borherhoff Mulder, 1998; Low, 2000a,b). In the United States, women trade off the acquisition of human capital and fertility; women who obtain higher levels of education have later ages of first birth and are more likely to remain childless.

Using simulations based on real-world data, it is suggested that wealth may confer two, and possibly three, demographic advantages. In some cases it leads, through the proximate mechanism of comparison with one's neighbors and peers, to greater intended fertility by individuals who perceive themselves as better off than their reference group. Several works suggest that couples make deliberate decisions about family size in response to their judgment of relative resources available and relative well-being; when deliberately chosen family sizes are considered, there is a correlation between income and family size. When accidental pregnancies are considered, the picture becomes less clear. Wealth can also protect children from some exogenous mortality (moving to safe neighborhoods), and endow them with costly competitive ad- vantages (Kaplan et al., 1995; Knodel et al., 1990). Finally, if new resources are allocated first and preferentially to alreadywealthy individuals, when resources become limiting, lineage failures will occur preferentially in poorer lineages. The first two advantages do not, in most western societies today, appear strong in terms of lineage persistence. The third is, at this point, speculative.

Finally, it is important to remember that population patterns arise from individual choices, and, as demographers know well, human intentionality matters. First, measuring even objective resources is, of course, a difficult task. Adding social resources, which may substitute for other physical and human capital in some constrained conditions, adds complexity. But objective measures may be less important in people's marriage and fertility choices than their perceived wealth trajectory, perceived comparative wealth, or perceived social wellbeing. For example, migrants from a relatively poorer to a relatively richer area may show fertility above native-born individuals of the rich area; the trend, rather than absolute value of resources, may be the relevant consideration.

In these analyses, total fertility was held equal across populations, and only mothers and daughters were considered. Another problem remains that clearly can influence offspring survival and reproductive success: patterns of investment across children. As Charnov (1982) noted, investment in offspring should maximize the predicted return from offspring. Under conditions of constricted resources, we might find very unequal investment in children within a family, with heightened investment in older (closer to successful reproduction) sons, whose success in most societies is more dependent on resources than daughters (Low, 2000b). In the Swedish case, for example, land was overwhelmingly given to the oldest adult son, despite legal "equal inheritance"; and land-owning men had more children than their landless brothers. Furthermore, not only are parental decisions influenced by resource conditions (Davis et al., 1999), but parental attempts to invest equally may have quite contrary, inequality-producing effects (Davis et al., 1999). The model derived here is flexible and could be modified for analysis of such questions. 
In the life histories of other species, delayed maturation and late fertility are seen only when these yield a net lineage reproductive profit (Stearns, 1992; Roff, 1992); optimal age at first reproduction is nonetheless not trivial to compute. When tradeoffs in human capital, resource acquisition trajectory, and fertility costs are explicitly modeled, the results can be complex.

For humans, it looks increasingly as though the decline in fertility that has accompanied industrialization, shifts in education, and changes in labor markets, is in fact, suboptimal from a reproductive point of view (cf. Borgerhoff Mulder, 1997; Pérusse, 1993; Vining, 1986). Note, however, that most studies use a variety of measures and proxies, and few recognize that we may not be defining "environments" and "populations" appropriately (see Low, 1993, 1999, 2000a; Hughes, 1988; Low and Clarke, 1993; Low et al., 1992; Simon, 1974; Freedman and Thornton, 1982; Johnson and Lean, 1985). It is still not clear whether the choices by a growing proportion of individuals to maximize physical resources, at the cost of delayed and often lowered fertility, are not simply maladaptive in a biological sense. Certainly the models presented here suggest that this may be true, depending on assumptions. However, such models must be made far more realistic and include more thorough considerations of extrinsic unpredictabilities, before this question can be addressed thoroughly.

\section{LITERATURE CITED}

Alexander RD. 1979. Darwinism and human affairs Seattle: University of Washington Press.

Alexander RD. 1987. The biology of moral systems. New York: Aldine de Gruyter.

Alexander RD. 1988. Evolutionary approaches to human behavior: What does the future hold? In: Betzig L, Borgerhoff Mulder M, Turke P, editor. Human reproductive behaviour: A Darwinian perspective. New York: Cambridge University Press. p 317-341.

Becker G. 1981. A treatise on the family. Cambridge, MA: Harvard University Press.

Becker GS. 1991. A treatise on the family (enlarged edition). Cambridge, MA: Harvard University Press.

Becker G, Lewis HG. 1974. Interaction between quantity and quality of children. In: Schultz TW, editor. Economics of the family: Marriage, children, and human capital. Chicago: University Chicago Press. p $81-90$.

Bock J. 1999. Evolutionary approaches to population: Implications for research and policy. Popul Environ 21:193-222.

Boone J, Kessler S. 1999. More status or more children? Social status, fertility reduction, and long-term fitness. Evol Hum Behav 20:257-277.
Borgerhoff Mulder M. 1987. On cultural and biological success: Kipsigis evidence. Anthropol 89:617-634.

Borgerhoff Mulder M. 1988a. Reproductive success in three Kipsigis cohorts. In Clutton-Brock TH, editor. Reproductive success. Chicago: University of Chicago Press. p 419-435.

Borgerhoff Mulder M. 1988b. Kipsigis bridewealth payments. In: Betzig L. Borgerhoff Mulder M, Turke P, editors. Human reproductive behavior: A Darwinian perspective. Cambridge: Cambridge University. Press, p 65-82.

Borgerhoff Mulder M. 1995. Bridewealth and its correlates. Curr Anthropol 36:573-603 (including commentary).

Borgerhoff Mulder M. 1998. Demographic transition: Are we any closer to an evolutionary explanation? TREE 13:266-270.

Burton LM. 1990. Teenage childbearing as an alternative life-course strategy in multigenerational Black families. Hum Nat 1:122-143.

Caldwell JC. 1982a. Theory of fertility decline. New York: Academic Press.

Caldwell, JC. 1982b. The wealth flows theory of fertility decline. In: Hohn C, Mackensen R, editors. Determinants of fertility trends: Theories re-examined. Liege, Belgium: Ordina Editions, p 169-188.

Caldwell, JC. 1983. Direct economic costs and benefits of children. In: Bulatao RA, Lee RD, editors. Determinants of fertility in developing countries, Vol. 1 New York: Academic Press. p 458-493.

Caldwell JC. 1996. Demography and social science. Popul Stud 50:305-333.

Chagnon N. 1988. Life histories, blood revenge, and warfare in a tribal population. Science 239:985-992.

Charnov EL. 1982. The theory of sex allocation. Princeton, NJ: Princeton University Press.

Charnov EL. 1993. Life history invariants. Oxford: Oxford University Press.

Clarke AL, Low B. 1992. Ecological correlates of human dispersal in 19th century Sweden. Animal Behav 44:677-693.

Coale AJ. 1974. The history of the human population. Sci Am (Sept 1974): 17-27.

Coale AJ, Trussell TJ. 1974. Model fertility schedules: Variations in the age structure of childbearing in human populations. Popul Index 40:185-258. (See also Erratum, Popul Index 41:572.)

Coale AJ, Trussell TJ. 1978. Technical note: Finding the two parameters that specify a model schedule of fertility. Popul Index 44:203-213.

Cohen JE. 1995. How many people can the earth support? New York:Norton.

Cohen JE. 1998. Can a more equal world support more or fewer people than a less equal one? Development Discussion Paper No. 628. Boston, MA: Harvard Institute International of Internat'l Development.

Corcoran M, Kunz JP. 1997. Do unmarried births among African-American teens lead to adult poverty? Soc Serv Rev June:274-287.

Cronk L. 1991a. Human behavioral ecology. Ann Rev Anthropol 20:25-53.

Cronk L. 1991b. Wealth, status, and reproductive success among the Mukogodo of Kenya. Am Anthropol 93:345-360.

Daly M, Wilson M. 1997. Life expectancy, economic inequality, homicide, and reproductive timing in Chicago neighborhoods. Bri J Med 314:12711274.

Darwin C.1871. The descent of man and selection in relation to sex, (2 vols). London: John Murray.

Davis JN, Hertwig R, Sulloway FJ. 1999. Parental investment and the inequality of equality. Paper pre- 
sented at the 1999 Evolution and Human Behavior meetings, Salt Lake City.

Davis, JN, Todd PM, Bullock S. (1999). Environmental quality predicts parental provisioning decisions. Proc R Soc London B 266:1791-1797.

Emlen ST. 1997. Predicting family dynamics in social vertebrates. In: Krebs JR, Davies NB, editors. Behavioural Ecology, 4th ed. Oxford: Blackwell Scientific. Chapter 10.

Essock-Vitale SM, McGuire MT. 1988. What 70 million years hath wrought: Sexual histories and reproductive success of a random sample of American women. In:Betzig L, Borgerhoff Mulder M, Turke P, editors. Human reproductive behaviour: A Darwinian perspective. Cambridge: Cambridge University Press $\mathrm{p}$ 221-235.

Fisher RA. 1958. The Genetical Theory of Natural Selection. New York: Dover.

Freedman DS, Thornton A. 1982. Income and fertility: The elusive relationship. Demography 19: 65-78.

Friedlander D, Okun BS, Segal S. 1999. The demographic transition then and now: Processes, perspectives, and analyses. J Fam Hist 24:493-533.

Geronimus AT. 1996a. Black/white differences in the relationship of maternal age to birthweight: A population-based test of the Weathering Hypothesis. Soc Sci Med 42:589-597.

Geronimus AT. 1996b. What teen mothers know. Hum Nat 7:323-352.

Geronimus AT. 1997. Teenage childbearing and personal responsibility. Polit Sci Quart 112:405-430.

Geronimus AT, Bound J, Waidmann TA. 1997. Health inequality, family caretaking systems, and population variation in fertility-timing. Paper presented at 1997 Annual Meeting of the Population Association of America, Washington, DC

Geronimus AT, Bound, J, Waidmann, TA, Hillemeier, MM, Burns PB. 1996. Excess mortality among Blacks and Whites in the United States. New Eng Med 335:1552-1558.

Hardin G. 1968. The tragedy of the commons. Science 162:1243-1248.

Hass N. 1999. We are family: Mom, dad, and just me. New York Times, Sunday 24 October 1999.

Heilig GK. 1996. How many people can be fed on earth? In: Lutz W, editor. The future population of the world: What can we assume today? revised and updated edition, International Institute of Applied Systems Analysis (IIASA), London: Earthscan Publications. p $196-250$

Hill K. 1993. Life history theory and evolutionary anthropology. Evol Anthropol 2:78-88.

Hill K, Hurtado AM. 1996. Ache life history: The ecology and demography of a foraging people. New York: Aldine De Gruyter.

Hughes AL. 1986. Reproductive success and occupational class in eighteenth-century Lancashire, England. Soc Biol 33:109-115.

Hughes AL. 1988. Evolution and human kinship. Oxford: Oxford University Press.

Irons W. 1979a. Natural selection, adaptation, and human social behavior. In: Chagnon NA, Irons W, editors. Evolutionary biology and human social behavior: An anthropological perspective. North Scituate, MA: Duxbury Press.

Irons W. 1979b. Emic and reproductive success. In: Chagnon NA, Irons W, editors. Evolutionary biology and human social behavior: An anthropological perspective. North Scituate, MA: Duxbury Press.

Irons W. 1983. Human female reproductive strategies. In: Wasser S, editor. Social Behavior of female vertebrates. New York: Academic Press.169-213.
Irons W. 1996. Morality, religion, and human nature. In: Richardson WM, Wildman W, editors. Religion and science: History, method, dialogue. New York: Routledge. p. 375-399.

Johnson NE, Lean S. 1985. Relative income, race and fertility. Popul Stud 39:99-112.

Kaplan H. 1994. Evolutionary and wealth flows theories of fertility: Empirical tests and new models. Popul Dev Rev 20:753-791.

Kaplan H. 1996. A theory of fertility and parental investment in traditional and modern human societies. Yrbk Phy Anthropol 39:91-135.

Kaplan H, Lancaster JB, Bock JA, Johnson SE. 1995. Fertility and fitness among Albuquerque men: A competitive labour market theory. In: Dunbar RIM, editor. Human reproductive decisions. London: St Martin's Press in association with the Galton Institute. p 96-136.

Kaplan H, Lancaster JB, Anderson KG. 1998. Human parental investment and fertility: The life histories of men in Albuquerque. In: Booth A, Crouter, N, editors. Men in families: When do they get involved? What difference does it make? New York: Lawrence Erlbaum. p 55-111.

Kaplan HS, Lancaster J. 2000. The life histories of men in Albuquerque: An evolutionary-economic analysis of parental investment and fertility in modern society. In: Cronk L, Irons W, Chagnon N, editors. Adaptation and human behavior: An anthropological perspective. Hawthorn, NY: Aldine de Gruyter.

Kirk D. 1996. Demographic transition theory. Popul Stud 50:361-387.

Knodel J, Havanon N, Sittitrai W. 1990. Family size and the education of children in the context of rapid fertility decline. Popul Dev Rev 16:31-62.

Lancaster J. 1986. Human adolescence and reproduction: An evolutionary perspective. In: Lancaster JB Hamburg BA, editors. School-age pregnancy and parenthood. New York: Aldine de Gruyter. p 1738

Lessels CM. 1991. The evolution of life history strategies. In: Krebs JR, Davies NB, editors. Behavioural ecology, 3rd ed. Oxford: Blackwell Scientific. p 32-68.

Low BS. 1989. Occupational status and reproductive behavior in 19th century Sweden: Locknevi parish. Soc Biol 36:82-101.

Low BS. 1990. Land ownership, occupational status, and reproductive behavior in 19th-century Sweden: Tuna parish. Am Anthropol 92:457-468.

Low BS. 1991. Reproductive life in nineteenth century Sweden: An evolutionary perspective on demographic phenomena. Ethol and Sociobiol 12:411-448.

Low BS. 1993. Ecological demography: A synthetic focus in evolutionary anthropology Evol Anthropol 1(5):106-112.

Low BS. 1998. The evolution of human life histories. In: Crawford C, editor. Handbook of evolutionary psychology: Ideas, Issues and Applications. Mahwah, NJ: Lawrence Elrbaum. p 131-161.

Low BS. 2000a. Sex, wealth, and fertility: Old rules, new environments. In: Cronk L. Chagnon N, Irons W, editors. Adaptation and human behavior: An anthropological perspective. Hawthorne, NY: Aldine de Gruyter.

Low BS. 2000b. Why sex matters. Princeton NJ: Princeton University Press

Low BS, Clarke, AL. 1991. Occupational status, land ownership, migration, and family patterns in 19thcentury Sweden. J fam Hist 16:117-138.

Low BS, Clarke AL. 1992. Resources and the life course: Patterns in the demographic transition. Ethol Sociobiol 13:463-494. 
Low BS, Clarke, AL, Lockridge K. 1992. Toward an ecological demography. Popul Dev Rev 18:1-31.

Low BS, Clarke AL. 1993. Historical perspectives on population and environment: Data from 19th century Sweden. In: Ness G, Drake W, Brechin S, editors. Population- environment Dynamics: Ideas and observations. Ann Arbor, MI: University of Michigan Press.

Low BS, Simon CP, Anderson KG. (in press). The biodemography of modern women: tradeoffs when resources become limiting. In Rodgers, JL and Kohler, HP, editors. The biodemography of human fertility and reproduction. Kluwer.

Luker K. 1996. Dubious conceptions: The Politics of Teenage Pregnancy. Cambridge, MA: Harvard University Press.

MacArthur RH, Wilson EO. 1967. The theory of island biogeography. Princeton NJ: Princeton University Press.

Mace R. 1993. Nomadic pastoralists adopt subsistence strategies that maximize long-term household survival. Behav Ecol 33:329-334.

Mace R. 1996. When to have another baby: A dynamic model of reproductive decision-making and evidence from Gabra pastoralists. Ethol Sociobiol 17:263-273.

Mace R. 1998. The coevolution of human fertility and wealth inheritance strategies. Phil Trans R Soc London Series B 353:389-397.

MacKellar FL. 1996. On human carrying capacity. PopulDev Revi 22:145-156.

MacKellar FL. 1997. Population and fairness. Popul Dev Rev 23:359-376.

Pérusse D. 1993. Cultural and reproductive success in industrial societies: Testing evolutionary hypotheses with behavioral data. Hum Nat 5:255-278.

Powell B, Steelman LC. 1989. The liability of having brothers: paying for college and the sex composition of the family. Socio Educ 62:134-147.

Rank MA. 1989. Fertility among women on welfare: Incidence and determinants. Am Socio Rev 54: 296-304

Roff D. 1992. The evolution of life histories: Theory and analysis. New York: Chapman Hall.

Rogers AR. 1990. The evolutionary economics of human reproduction. Ethol Sociobiol 11:479-495.

Rogers AR. 1991. Conserving resources for children Hum Nat 2:73-82.

Rogers AR. 1995. For love or money: The evolution of reproductive and material motivations. In: Dunbar RIM, editor. Human reproductive decisions. London:
St Martin's Press, in association with the Galton Institute. p 76-95.

Røskaft E, Wara A, Viken A. 1992. Reproductive success in relation to resource-access and parental age in a small norwegian farming parish during the period 1700-1900. Ethol Sociobiol 13:443-461.

Schofield R, Coleman D. 1986. The state of population theory. In Coleman D, Schofield R, editors. The State of Population Theory. Oxford: Basil Blackwell p 1-13.

Sellers P. 1998. The 50 most powerful women in American business. Fortune October 12, 1998: 76-86. Sibley RM, Calow P. 1986. Physiological ecology of animals: An Evolutionary Approach Oxford: Blackwell Scientific.

Simon J. 1974. The effects of income on fertility. Carolina Population Center Monograph 19. Chapel Hill NC: University of North Carolina Press.

Smith CC. 1974. The optimal balance between size and number of offspring. Am Natural 108:499-506.

Stack CB. 1974. All our kin. New York: Harper and Row.

Stack CB. 1996. Call to home. New York: Basic Books.

Stearns S. 1992. The evolution of life histories. Oxford: Oxford University Press.

Tasiran AC. 1995. Fertility dynamics: Spacing and timing of Births in Sweden and the United States. Amsterdam: Elsevier.

Turke PW. 1989. Evolution and the demand for children. Popul Dev Rev 15:61-90.

Turke PW. 1992. Theory and evidence on wealth flows and old-age security: A reply to Fricke. Popul Dev 17:689-702.

Vining DR. 1986. Social versus reproductive success: The central theoretical problem of human sociobiology. Behav Brain Sci 9:167-187.

Voland E. 1990. Differential reproductive success within the Krummhörn population (Germany, 18th and 19th centuries). Behav Ecol Sociobiol 26:65-72.

Voland E, Siegelkow E, Engel C. 1990. Cost/benefit oriented parental investment by high status families: The Krummhörn case. Ethol Sociobiol 12:105 $-118$.

Voland E, Dunbar RIM. 1995. Resource competition and reproduction: The relationship between economic and parental strategies in the Krummhörn population (1720-1874). Hum Nat 6:33-49.

Williams GC. 1966. Adaptation and natural selection. Princeton, NJ: Princeton University Press.

Willis RJ. 1973. A new approach to the economic theory of fertility behavior. J Polit Econ 81:S14-S69. 